\title{
The Inter Business Index: Developing a Tool for Measurement and Comparability of Holistic Sustainability in Businesses
}

\author{
Johanna Hallin $^{1}$, Michelle Sandberg ${ }^{2} \&$ Nathalie Ahlstedt Mantel ${ }^{3}$ \\ ${ }^{1}$ Umeå, Sweden \\ ${ }^{2}$ Stockholm, Sweden \\ ${ }^{3}$ Stockholm, Sweden \\ Correspondence: Michelle Sandberg, Stockholm, Sweden. E-mail: michelle@lumenbehavior.com
}

Received: March 1, 2017 Accepted: March 25, 2017 Online Published: May 29, 2017

doi:10.5539/jms.v7n2p27 URL: http://doi.org/10.5539/jms.v7n2p27

\begin{abstract}
The scope of sustainable development is undoubtedly growing, and becoming increasingly more important due to the process of globalization, amounting in complex environmental, societal and economic issues. Although the subject of business sustainability has been gaining traction and resulted in increased knowledge in the field, the business sustainability discourse is still at a young stage, where the different streams of approaches, definitions, systems and measures are fragmented and challenged. Today's global challenges are so large and complex that they require a new kind of problem-solving and way of doing business. Identifying solutions requires a diversity of perspectives, approaches and capabilities, and the business sector plays a critical role. The integrated approach has been examined to some extent, proposing a holistic manner of moving on to true business sustainability, and a sustainable development on a global scale. This article presents the concept of Inter Business and the Inter Business Index, a tool for measurement and comparability of holistic sustainability in businesses. The Inter Business framework consists of four key-components that describe the skills needed for future-preparedness. In our research, we have analysed the 50 biggest corporations in Sweden and identified purpose, empathy, system approach and transformation as components that respond to the hypothesis that interconnection and integration are key for companies to survive and thrive, whilst contributing to society at large.
\end{abstract}

Keywords: business sustainability, business transformation, empathy, inter business, inter business index, purpose, sustainable development, system approach, transformation

\section{Introduction}

\subsection{The Concept of Sustainability}

The scope of sustainable development is undoubtedly growing, and becoming increasingly more important due to the process of globalization, amounting in complex environmental, societal and economic issues. Sustainability is a debated concept that is hard to define and varies in meaning for different people (White, 2013). The most commonly shared definition of the term sustainable development was first described in 1987 in Our common future, also know as "The Brundtland Report". Sustainable development was defined as a "development that meets the needs of the present without compromising the ability of future generations to meet their own needs". When referring to sustainability in practice and business sustainability, a concept often encountered is "the triple bottom line". Coined in 1994 by John Elkington, the triple bottom line consists of the three P's - people, planet and profit, which entail measuring environmental, social and economic performance in businesses.

Although the subject of business sustainability has been gaining traction and resulted in increased knowledge in the field, the business sustainability discourse is still at a young stage, where the different streams of approaches, definitions, systems and measures are fragmented and challenged (Dyllick \& Muff, 2016). We want to further explore the interconnections and interactions between the different dimensions of sustainability.We argue that altogether excluding the interdependence and interconnection between the various aspects of sustainability is equivalent to excluding the whole concept of sustainability. Different elements of sustainability do not act as isolated dimensions, making this approach insufficient to achieve a truly sustainable business and sustainable development on a global scale (Symons \& Lamberton, 2014). This calls for new approaches, not only to the concept of sustainability, but also to ways and methods to measure the full scope of sustainability in businesses. 


\subsection{Targeting Businesses}

Today's global challenges are so large and complex that they require a new kind of problem-solving and way of doing business. Identifying solutions requires a diversity of perspectives, approaches and capabilities, and the business sector plays a critical role. Businesses are not only entities that respond to the environment, but they also affect the environment and earth in a direct way (Ehrlich \& Ehrlich, 1987; Svensson \& Wagner, 2011). Companies have an immense impact on society, and business activities have caused many of the problems we face today, making them influential actors in the pursuit of sustainable development on a global scale (Schaltegger, Lüdeke-Freund, \& Hansen, 2016). This was made even clearer by the EU Commission in 2016, when the adoption of directive 2014/95/EU made it mandatory for large public entities in the EU to disclose non-financial information. Businesses today are not only exposed to more regulations regarding sustainability efforts and disclosure - higher expectations, norms and demands from society, stakeholders (Caprar \& Neville, 2012), and investors alike put further pressure on businesses, where they must conform to survive and stay profitable (Rezaee, 2016).

It is widely acknowledged that companies play an important role in shaping and transforming not only markets, but also society. Businesses have the resources and political power that can help contribute to sustainable development (Shrivastava, 1995; Asif, Searcy, Garvare, \& Ahmad, 2011). Frontrunners and pioneers of sustainable business can, in turn, also exert influence and pressure on markets and other businesses, acting as change agents in a way that may sometimes even be more influential and effective than regulators or NGOs (Schaltegger et al., 2016). More importantly, corporations have the means and capacity to effectively address such issues and create conditions for human wellbeing and global welfare in a way that few other actors can. Despite this, there's still a disconnection between science and practice, and a lack of practical tools highlighting businesses as actors in solving our contemporary sustainability issues. Sustainability in most businesses is acknowledged as something important not only for competitive advantages, but something even indispensable for future survival of businesses. Yet their efforts and impact have not been creating the necessary improvements on a larger, global scale and most fail to provide for social and environmental needs (Metcalf \& Benn, 2012; Rake \& Grayson, 2009). This causes a significant disconnection between, on the one hand, what a company says that it should and wants to do, and on the other hand, its actual actions and their subsequent impacts (Dyllick \& Muff, 2016). Dimensions of sustainability in business is often viewed and measured separately, overlooking the interdependence amongst all the elements of sustainability and with a prominent focus on financial performance (Høgevold \& Svensson, 2016).

While there is an extensive awareness of the interdependence between the sustainability dimensions, the literature and current frameworks often view these as separate entities without mutual effects, overlooking the system which they are part of. This causes an over-simplification of the actual reality facing businesses today and ahead (Gao \& Bansal, 2013). Businesses are not only affected by constraints imposed by the past, but they will also need to adapt in order to meet new challenges and demands in the future. The fossil fuel industry is a contemporary example of a sector that will need to adapt to a changing market characterized by higher demands on a sustainable product and standardizations of new innovations that challenge their position, such as renewable energy sources.

\subsection{Introducing an Integrated Perspective}

The integrated approach has been examined to some extent, proposing a holistic manner of moving on to true business sustainability, and a sustainable development on a global scale. Previous studies have also stressed the importance of embedding sustainability in the core of the business and throughout all operations and strategy as a way to make a significant change (Schaltegger et al., 2016; Belz \& Peattie, 2012; Eccles, Miller Perkins, \& Serafeim, 2012; Epstein, 2008; Esty \& Winston, 2009; Laszlo \& Zhexembayeva, 2011; Smith \& Lensen, 2009; Dyllick \& Muff, 2016). Many of the pioneers in business sustainability have integrated sustainability in the core of their business models (Hall, Daneke, \& Lenox, 2010; Jolink \& Niesten, 2015; Schaltegger et al., 2016).

Understanding a company requires a measurement tool to track the holistic context, and one way to access this knowledge is to measure the skills that will take the company through future challenges. Applying an integrative and holistic logic to sustainability makes it more likely for businesses to consider possible connections not only between different aspects of sustainability, but also different events taking place over time (Gao \& Bansal, 2013). An integrated approach to business sustainability can help companies confront, adapt and respond effectively to the increasing amount of complex and interconnected sustainability issues facing them today. It is however important to view them as part of a system, and analyse them together, including their interdependencies - even though it is not always clear how the interactions may occur and look (Wagenhals, Garner, Duckers, \& Kuhn, 2014). Sustainability issues and aspects do not work as well-aligned and isolated elements, and businesses need to transcend intoviewing their business in a holistic way. The 17 Sustainable Development Goals presented by the UN in 2015 mark a heightened and systemized ambition for sustainable development that include government, 
business and individuals alike. In addition to this, all aspects are interconnected, and they interact and influence each other and change over time. This article presents the concept of Inter Business and the Inter Business Index, a tool for measurement and comparability of holistic sustainability in businesses. The Inter Business Index builds upon the framework of the Human Centered Business Index, which has its roots in human-centered design, social innovation and systems change, and highlights the holistic approach to businesses (Hallin, Fredriksson, Altman, \& Zhou, 2016). The previous concepts and methods of Human Centered Business and the Human Centered Business Index has over the course of 2016 been evaluated, revised and renewed to form the Inter Business Index, an even more comprehensive tool of analysis for measurement and comparison of holistic business sustainability.

\subsection{The Four Key-components of Inter Business}

The Inter Business framework consists of four key-components that describe the skills needed for future-preparedness. In our research, we have identified purpose, empathy, system approach and transformation as components that respond to the hypothesis that interconnection and integration are the keys for companies to survive and thrive, whilst contributing to society at large. Using them as a benchmark and criteria for Inter Business, we have designed indicators that are easy to use and understand - applicable on any business, sector or market. This framework focuses on analysing the integration and interconnectedness of sustainability aspects in strategic priorities, stakeholder dialogue and external communication of the company-bringing about a holistic view of the future preparedness of any company, market or sector analysed.

\subsubsection{Purpose}

Purpose is related to the meaning derived from carrying forward values-driven work. The purpose of the business activity needs to be described and acted on in relation to core business, and the company's actions need to align with - not deviate from - this purpose (Hallin et al., 2016). Knowing your purpose therefore requires a clear and consistent understanding of what the company is about. Understanding what the company is about makes it possible to not only work, but to work with intention and with a shared cause (Schultz, 2014). The purpose of business is rarely about being money making machines (White, Yakis-Douglas, Helanummi-Cole, \& Ventresca, 2017) - in fact, several long-established and successful businesses started out with the purpose of providing useful, and sometimes even crucial, services to people and the common good (Dyllick \& Muff, 2016; Symons \& Lamberton, 2014). The need to bring purpose to the core of strategy and operations is at the centre of holistic sustainability work. Focusing on purpose acknowledges the interconnection of both business and society, both of which are dependent on, and cannot thrive without, the other (Hollensbe, Wookey, Hickey, George, \& Nichols, 2014).

\subsubsection{Empathy}

Empathy represents the ability to place oneself in the shoes of the stakeholder, allowing us the share the experience of others (Pavlovich \& Krahnke, 2012). We argue that the skill of empathy should be embraced as a foundational element of better business. An Inter Business company is aware of the significance of empathy delivered to the entire marketplace, from customers and employees to the public. Empathy can be taught and learned through various interactions in different formal and informal contexts (Holt \& Marques, 2012). Empathy helps businesses see matters from the stakeholders' view (Gorry \& Westbrook, 2011), and enhances interactions, drives cooperation and sharing of resources and knowledge to help others (de Vignemont \& Singer 2006; Hosking \& Fineman, 1990; Van Lange, 2008; Pavlovich \& Krahnke, 2012). This principle is widely recognized as crucial; empathetic human connection compels people to act on others' behalf, and innovation that stems from empathy becomes more meaningful on the market (Tim Urmston, interview, November 10, 2015; Hallin et al., 2016). This form of respect, humility and empathy has clear implications for businesses and organizations, who must remain conscious of the fact that they themselves are not the audience for their solutions; ultimately, the goal of bringing solutions and products to the marketplace is to improve peoples' lives, not to simply make organizations more profitable or efficient (Chokdee Rutirasiri, interview, October 16, 2015; Hallin et al., 2016).

\subsubsection{System Approach}

In order to move away from "linear" forms of thinking-where the emphasis is on "fixing" isolated problems - towards a holistic view of sustainability, businesses and organizations must embrace what we have defined as a system approach. The need for integrating a system approach in business reaches further than securing the future of a company's position in the marketplace - it is also about consumer insight and preference. Consumers experience full experiences, not siloed segments of experiences, even though companies for long have perceived sustainability and social mission segregated from core business (Chokdee Rutirasiri, interview, October 16, 2015; Hallin et al., 2016). Many of our global issues are a result of decisions implemented in the past with a myopic and limited approach to possible effects. Businesses are part of society, and responsibility for 
human development and wellbeing has been increasingly assigned to companies (Rüdiger, 2011). To fully do this, businesses need to holistically take account of all the different aspects that affect and interact with each other, and consider the whole system that they are a part of (Barile, Saviano, Landolo, \& Calabrese, 2014). Businesses therefore need to adopt a system approach to better understand and predict possible outcomes of their decisions (Arnold \& Wade, 2015).

\subsubsection{Transformation}

Transformation - the act or process of changing from one state to another, is essential for businesses to survive and thrive in a future context. The field of business transformation is about making changes to meet new circumstances and external factors like new markets, challenges and demands. Although there is no "silver bullet solution" to secure the future survival of a company, research have defined certain business characteristics or skills of companies that influence the success of a business transformation and future survival. Some of those identified skills and/or characteristics are: The "right" culture and leadership, ability to innovate, willingness to learn, and a holistic approach to their business activity (Müller \& Pfegler, 2014; Cowan-Sahadath, 2010; Philip \& Mckeown, 2003). Companies today exist in a global context with a highly present technological transformation occurring. Business affect and are affected by more factors than they did just acting on local and regional markets, making it imperative to adapt and innovate to be able to stay competitive and even survive (Pahurkar, 2014). This makes it impossible for businesses to main a status quo, and the skills of transformation are necessary in navigating ways forward, and forging new ones.

\section{Methodology}

The basis of the Inter Business analysis and framework is based on the Human Centered Business Index-whose first results were published in the Human Centered Business Index Report 2016, identifying the frontrunners in business beyond sustainability in Sweden. Since then, the framework and the construction of the measurement has been calibrated and updated, providing a practical tool for a holistic sustainability measurement and comparability across sectors (Hallin et al., 2016).

The following sections will describe the previous work of the Human Centered Business Index in brief, and present the full Inter Business analysis based on the reprocessing of both concept and measurement tools.

\subsection{Materials}

The Human Centered Business Index has been key in developing the Inter Business framework. The empirical research that was conducted between the years of 2014 and 2016 brought about insight into key-components that constitute a holistically sustainable business, as well as the consumer and researcher interviews that informed the first version of the measurement tool. Key insights included the importance of capturing the subjective experiences of the respondent, moving away from linear forms of solving issues, and innovating for a changing context (Hallin et al., 2016).

In re-calibrating and updating the Index, we have used publically available materials from Sweden's 50 biggest companies in the year of 2016, such as social media feeds, annual reports, sustainability reports and communications material in the form of press releases from the individual companies that we have analysed. Many businesses today use the internet and different social media outlets to not only communicate results to stockholders, but also as a means to reach and respond to customers and other stakeholders. Much of the interactions to and with businesses have moved online, making this a considerable source of information. The selection of the materials is chosen systematically, providing high reliability in the data-gathering process. The material for the Inter Business analysis conducted on Sweden's 50 biggest companies was gathered during the months of September and October of 2016. The annual reports and sustainability reports used in the analysis are published publically, and was retrieved from each company's official website. The press material was gathered from their official media outlet provider, and the social media interactions were compiled from their official corporate Twitter and Facebook accounts. The purpose survey was sent out through a link online in October, with almost 300 respondents from across Sweden. The analysis of the entire Inter Business analysis of the 50 companies was finalized in November 2016.

\subsection{The Inter Business Analysis}

The Inter Business Index measurement consists of four distinct indices specific to each key-component of Inter Business. Each component specific index is composed of two analyses; one analysis of the overarching strategy (core index), and one that separately measures each specific key-component of Inter Business. The core index measurement is based on an in-depth qualitative analysis of publicly available annual reports, and when applicable, separate sustainability reports. The most recent report is used as material for the analysis. The following 13 
indicators are assessed from the four principles of Inter Business:

Table 1. Core Index indicators.

\begin{tabular}{|c|c|}
\hline Mission and vision & $\begin{array}{l}\text { How well are the four principles represented in the vision and mission statements of the } \\
\text { company? }\end{array}$ \\
\hline Values & How well are the principles represented in the stated values of the company? \\
\hline Strategy & $\begin{array}{l}\text { How well are the principles represented in the strategy moving forward? Are they taken into } \\
\text { account when planning ahead? }\end{array}$ \\
\hline Main services and products & $\begin{array}{l}\text { How are the construction of the services and products aligned with the principles? Are they } \\
\text { sustainable, made with empathy for the customer, innovative and aligned with the core mission of } \\
\text { the company? }\end{array}$ \\
\hline Results & $\begin{array}{l}\text { Is the company profitable? (Economic sustainability is a important indicator of a sustainable } \\
\text { company as a whole) A yes/no question. }\end{array}$ \\
\hline Approach & How do they approach their goals_-and move towards their vision? \\
\hline Priorities & How does the company prioritize their agenda and actions? \\
\hline Transparency & Is all material available and is it extensive enough to perform the analysis? A yes/no question. \\
\hline Sustainability context & $\begin{array}{l}\text { Does the company understand and recognize their part in the system, the world around them? Do } \\
\text { they understand the global challenges ahead and have a plan to help solve them? }\end{array}$ \\
\hline Stakeholder inclusiveness & $\begin{array}{l}\text { How do they interact with their stakeholders, and how are the voices of the stakeholders heard in } \\
\text { the work that the company is doing? }\end{array}$ \\
\hline Key Assets & Do they mention their key assets - if so- — which do they highlight as most important? \\
\hline $\begin{array}{l}\text { Diversity in board } \\
\text { composition }\end{array}$ & How is the board divided in regard to gender? \\
\hline Corporate Governance & $\begin{array}{l}\text { Is there anything to suggest that the company is incorporating these principles into their corporate } \\
\text { governance-leading the way in the field? }\end{array}$ \\
\hline
\end{tabular}

The core business index brings an overarching and comprehensive overview of alignment, looking at a company's relationship to the four Inter Business principles (purpose, empathy, system approach and transformation) in their core business strategy. The annual reports (alongside the sustainability report, when applicable) is and should be a company's main forum for setting out and communicating long-term strategy to a complex stakeholder map. Using only readily available data therefore gives an indication of how well the company is capable of interacting with external stakeholders. The key-component measurements are stakeholder measurement that consists of a market survey, analysis of social media interactions, in-depth content analysis and a media analysis. Each of the stakeholder measurements is thoroughly described in the following sections of the each key-component specific analysis.

\subsubsection{The Purpose Analysis}

\subsubsection{Core}

The core analysis is a qualitative analysis of publicly available materials, such as annual reports, and when applicable also sustainability reports. The materials are measured against the thirteen indicators, and how well they align with the Inter Business key-component purpose. This creates an image of purpose related to the company's own view of the future and strategy forward.

The scoring is judged on whether purpose is present to a low, moderate, high or consistent extent with each of the thirteen indicators, and is given 1 point per indicator.

\subsubsection{Market Survey}

The Purpose Index stakeholder measurement consists of a market survey with two questions. The intent of this is to find out how the respondents think the company lives up to its perceived purpose, and how engaging that purpose is. To have a purpose that aligns with the perception of the company means that the company really does what it intends to do, the reason why it was created in the first place. To have an engaging purpose means that the purpose is well described, well-formulated and appealing. The Purpose analysis provides a measurement that is contemporary by showing how well the communicated purpose of a company relates to the norms and standards of stakeholders today. The survey begins with showing the company and its purpose to the respondent- - followed by the question "How well does this purpose align with your understanding of the company?" and with a second question, "How engaging is this purpose?". The respondents are subsequently asked to rate both alignment and engagement of the company's purpose on a scale of 1-5, with 1 being not aligned or engaging at all, to 5 being very aligned and engaging. 


\subsubsection{Scoring}

The total scoring of the purpose analysis is an aggregated result of the medium value of core analysis and medium value of market survey. A medium value of the respondent's views is weighed together, with the medium value of the core analysis to create a score for the purpose analysis.

Each indicator is rated 0-100 percent and total score is the medium value of both measurements.

\subsubsection{The Empathy Analysis}

\subsubsection{Core}

The core analysis is a qualitative analysis of publicly available materials, such as the annual report and/or sustainability report. The materials are measured against the thirteen indicators and how well they align with the Inter Business key-component empathy. This creates an image of purpose related to the company's own view of the future and strategy forward.

The scoring is judged on whether purpose is present to a low, moderate, high or consistent extent with each of the thirteen indicators, and is given 1 point per indicator.

\subsubsection{Social Media Analysis}

The Empathy index stakeholder measurement consists of a qualitative analysis of a company's social media interactions and rating them on a scale from attacking, defensive, sympathetic, empathic and neutral. We analyse interactions and assess in what way the company respond to their stakeholders, if the response is pleasant or unpleasant $—$ or if they do not respond at all. The types of responses are categorized according to the following criteria:

- Attacking/offensive

- Defensive

- Sympathetic

- Empathic

- Neutral

- No response

(Examples of interactions and judging can be found in Appendix A).

The material is taken from a company's official Facebook or Twitter-feeds, and is constituted by publically visible questions, remarks or insights shared by stakeholders.

The social media analysis provides an overview of the willingness of a company to meet, listen and learn from their stakeholders. Inadequate or total absence of communication implies introversion and inability to understand and implement knowledge from the stakeholders as lessons. A high score in the empathy index implies a well functioning ability to understand stakeholder knowledge, and an ability to capture the subjective experiences of stakeholders.

The interactions are scored as:

\begin{tabular}{ll}
\hline Empathic & 10 points \\
\hline Sympathetic & 4 points \\
Neutral & 2 points \\
Non-responsive & minus 1 point \\
Defensive & minus 4 points \\
Attacking & minus 10 points \\
\hline
\end{tabular}

Maximum total score of the social media analysis is 300 points, which is equivalent to 100 percent.

\subsubsection{Scoring}

The total score in empathy can be negative. When summarizing core analysis and the social media measurement, the measurement can be negative, but the end result is always a minimum 0 .

The total scoring of the purpose analysis is an aggregated result of the medium value of core analysis and medium value of the social media analysis. A medium value of the respondent's views is weighed together, with the medium value of the core analysis to create a score for the empathy analysis. 
Each indicator is rated 0-100 percent and total score is the medium value of those two.

\subsubsection{The System Approach Analysis}

\subsubsection{Core}

The core analysis is a qualitative analysis of publicly available materials, such as the annual report and/or sustainability report. The materials are measured against the thirteen indicators and how well they align with the Inter Business key-component system approach. This creates an image of purpose related to the company's own view of the future and strategy forward.

The scoring is judged on whether purpose is present to a low, moderate, high or consistent extent with each of the thirteen indicators, and is given 1 point per indicator.

\subsubsection{Content Analysis}

The System Approach Index measurement also consist of an an in-depth qualitative analysis of the annual report, focusing on four main areas of analysis, that is if the company:

- Moves towards a holistic (non-linear, non-isolated) view of sustainability, assessing performance and progress using required practices for the future as benchmarks.

- Displays a genuine understanding of one's responsibility and place in the system.

- Makes a thorough attempt to understand, define and analyse the problem in depth.

- Maintains a steady connection to, and a firm gaze on, the surrounding world.

The rationale of the system approach index finds support in the Future-Fit Business Benchmark, containing 21 future fit goals - shifting from today's best practice towards tomorrow's required practices. With this logic, relative progress compared with peers or past performance is rendered irrelevant - the only progress that truly matters is progress that reaches, or goes beyond, a future benchmark. In order to move away from "linear" forms of thinking, where the emphasis is on "fixing" isolated problems - towards a holistic view of sustainability, businesses and organizations must embrace a system approach.

The following four criteria are the ones we use to assess a company's level of system approach:

- The company considers future needs and requirements

- The company recognizes its responsibility, its change agency, and its place in the system

- The company defines and analyses the problem(s) in a manner that is "on purpose" and specific

- The strategic priorities are aligned with the definition and analysis of the problem

The scoring of the result is presented on each of the four criteria as:

\begin{tabular}{ll}
\hline Does not apply a system approach & 1 points \\
\hline Do apply a system approach from time to time & 2 points \\
Consistently applies a system approach & 5 points \\
\hline
\end{tabular}

\subsubsection{Scoring}

The total scoring of the system approach analysis is an aggregated result of the medium value of core analysis and medium value of the content analysis. A medium value of the respondent's views is weighed together, with the medium value of the core analysis to create a score for the system approach analysis.

Each indicator is rated 0-100 percent and total score is the medium value of both measurements.

\subsubsection{The Transformation Analysis}

\subsubsection{Core}

The core analysis is a qualitative analysis of publicly available materials, such as the annual report and/or sustainability report. The materials are measured against the thirteen indicators and how well they align with the Inter Business key-component transformation. This creates an image of transformation related to the company's own view of the future and strategy forward.

The scoring is judged on whether transformation is present to a low, moderate, high or consistent extent with each of the thirteen indicators, and is given 1 point per indicator. 


\subsubsection{Media Analysis}

The transformation Index measurement also consist of a qualitative media analysis, using the company's own 20 latest press releases to determine the presence of innovation, willingness to learn from past mistakes, and culture of change in the company.

The transformation index measures the company's communication on willingness to transform and adapt to constraints imposed by the past, as well as future needs. The process of the analysis can be described as a checklist, where the presence of following criteria are assessed and scored:

- The company innovates in sustainable future markets.

- The company reflects on the past in order to learn from mistakes and take action towards the future.

- The company has a tolerant, accepting and progressive corporate culture conducive to change, and where loyalty towards purpose trumps loyalty towards existing structures.

The presence of indicators are scored as:

\begin{tabular}{ll}
\hline 0 indicators & 0 points \\
\hline 1 indicator & 4 points \\
2 indicators & 4.5 points \\
3 indicators & 5 points \\
\hline
\end{tabular}

Maximum total score of the media analysis is 100 points, which is equivalent to 100 percent.

\subsubsection{Scoring}

The total scoring of the transformation analysis is an aggregated result of the medium value of core analysis and medium value of the media analysis. A medium value of the respondent's views is weighed together, with the medium value of the core analysis to create a score for the transformation analysis.

Each indicator is rated 0-100 percent and total score is the medium value of both measurements.

\section{Results}

The Inter Business analysis on Sweden's 50 biggest companies resulted in a ranking, built on percentage of alignment with the four key-components of Inter Business framework. Every company received a compiled ranking as well as a separate ranking in relation to each of the four components.

Table 2. Compiled ranking of the inter business index analysis

\begin{tabular}{lll}
\hline Ranking & Company Name & IBX \\
\hline 1. & KF & $66 \%$ \\
2. & Lantmännen & $64 \%$ \\
3. & Stora Enso & $61 \%$ \\
4. & H\&M & $61 \%$ \\
5. & Telia Sonera & $60 \%$ \\
6. & Folksamgruppen & $55 \%$ \\
7. & SEB & $54 \%$ \\
8. & Länsförsäkringar & $52 \%$ \\
9. & ICA gruppen & $52 \%$ \\
10. & Husqvarna & $49 \%$ \\
11. & Axfood & $49 \%$ \\
12. & Peab & $48 \%$ \\
13. & Alecta & $48 \%$ \\
14. & Stena & $47 \%$ \\
15. & Volvo Cars & $47 \%$ \\
16. & SKF & $46 \%$ \\
17. & Swedbank & $44 \%$ \\
18. & Astra Zeneca & $44 \%$ \\
19. & Skanska & $41 \%$ \\
20. & NCC & $40 \%$ \\
21. & E-on & $39 \%$ \\
22. & Scania & $39 \%$ \\
\hline
\end{tabular}




\begin{tabular}{lll}
\hline 23. & Nordea & $39 \%$ \\
24. & Axel Johnsson & $38 \%$ \\
25. & Ericsson & $38 \%$ \\
26. & ABB & $37 \%$ \\
27. & Volvo & $36 \%$ \\
28. & Preem & $36 \%$ \\
29. & Autoliv & $36 \%$ \\
30. & PostNord & $35 \%$ \\
31. & SCA & $35 \%$ \\
32. & AlfaLaval & $35 \%$ \\
33. & Electrolux & $33 \%$ \\
34. & Assa Abloy & $33 \%$ \\
35. & Vattenfall & $32 \%$ \\
36. & Sas & $31 \%$ \\
37. & Atlas Copco & $31 \%$ \\
38. & Securitas & $28 \%$ \\
39. & Ratos & $27 \%$ \\
40. & Handelsbanken & $26 \%$ \\
41. & SSAB & $26 \%$ \\
42. & Sandvik & $26 \%$ \\
43. & Boliden & $26 \%$ \\
44. & IF Skadeförsäkring & $24 \%$ \\
45. & Circle K & $22 \%$ \\
46. & Investor & $21 \%$ \\
47. & SonyMobile Communications & $20 \%$ \\
48. & Getinge & $20 \%$ \\
49. & Nordstjernan & $14 \%$ \\
50. & Carl Bennet & $2 \%$ \\
\hline
\end{tabular}

\subsection{Graphs}

As each company has been individually analysed for each key-component, it has become evident that only a few companies have had the ability to incorporate all principles successfully in their core business.

The graphs show the frontrunner of each of the principles, and also the levels of dispersion amongst the 50 companies on each principle.

\subsubsection{Inter Business}

The company ranking highest in the overall measurement of all of the four key-components of the Inter Business, was $\mathrm{KF}$, receiving a total score of 66 percent.

\section{KF \\ Total Score $66 \%$}

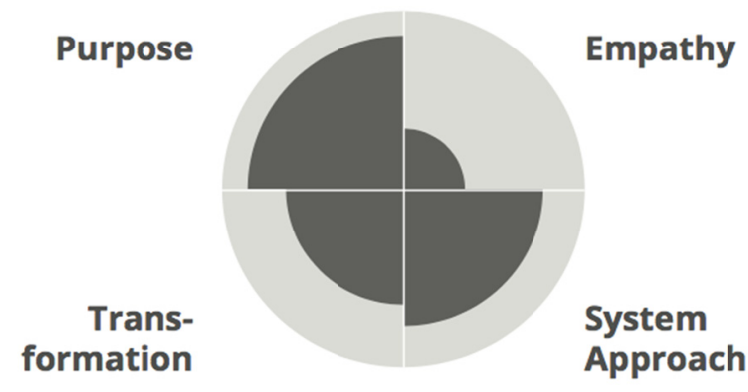

Figure 1. Inter business KF graph

The dispersion graph shows the variation on the scoring between the 50 companies. 


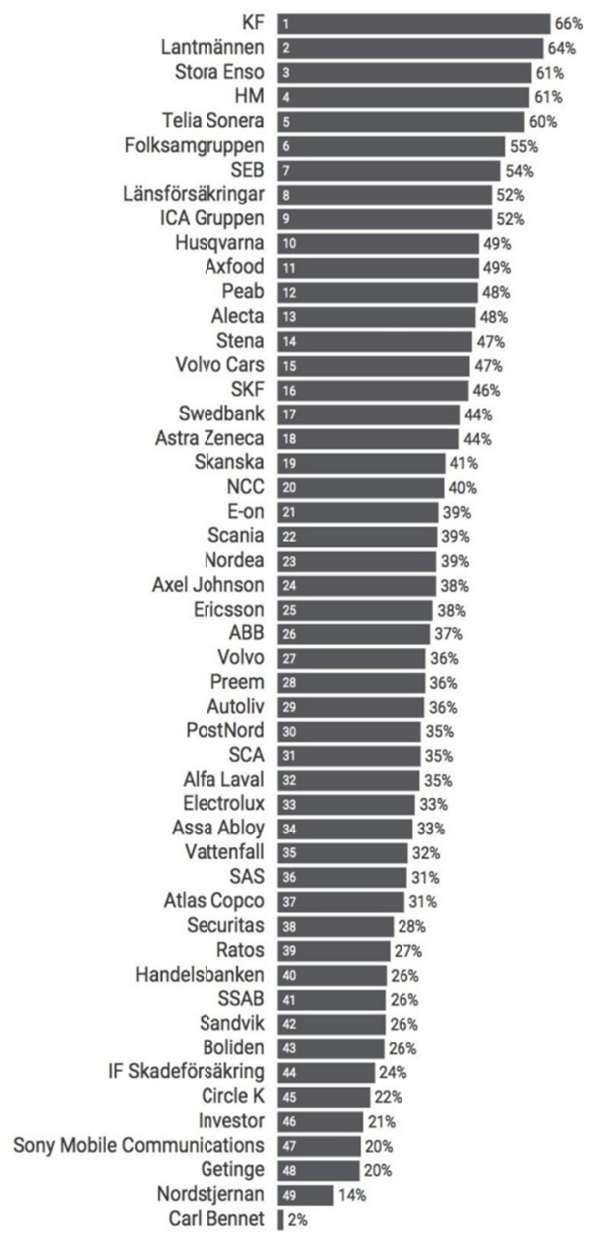

Figure 2. Inter business results graph

\subsubsection{Purpose}

The company that excelled in the purpose measurement was KF, receiving a total score of 86 percent.

\section{Purpose kf $86 \%$}

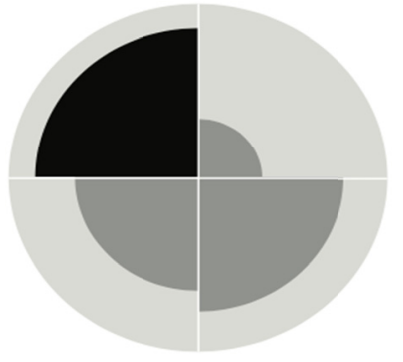

Figure 2. Purpose KF graph

The dispersion graph shows the variation on purpose between the 50 companies. 


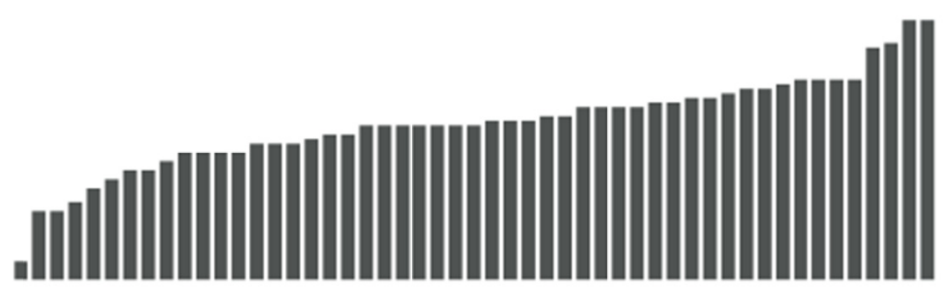

Figure 3. Purpose dispersion graph

\subsubsection{Empathy}

The company that excelled in the empathy measurement was Telia Sonera, receiving a total score of 86 percent.

\section{Empathy Telia Sonera 86\%}

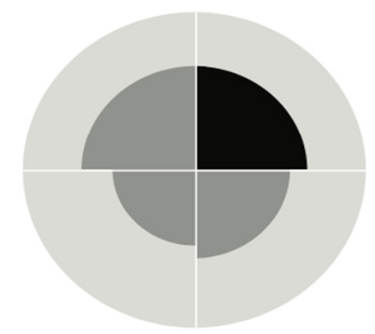

Figure 4. Empathy Telia Sonera graph

The dispersion graph shows the variation on empathy between the 50 companies.

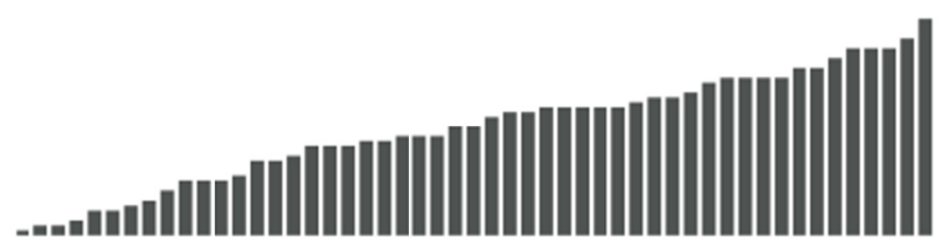

Figure 5. Empathy dispersion graph

\subsubsection{System Approach}

The company that excelled in the system approach measurement was KF, receiving a total score of 77 percent.

\section{System Approach $\mathrm{kF} 77 \%$}

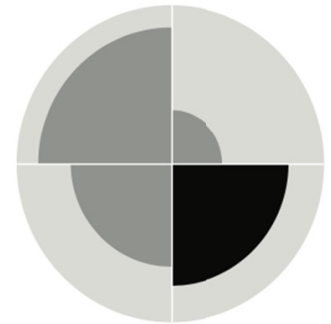

Figure 6. System approach KF graph 
The dispersion graph shows the variation on system approach between the 50 companies.

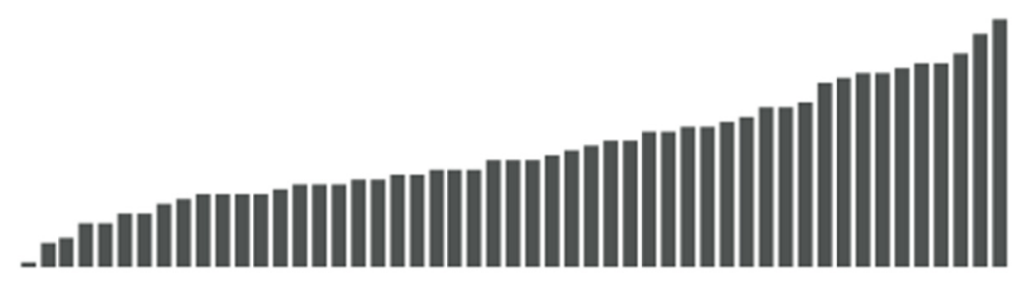

Figure 7. System approach dispersion graph

\subsubsection{Transformation}

The company that excelled in the system approach measurement was again KF, receiving a total score of 65 percent.

\section{Transformation KF $65 \%^{2}$}

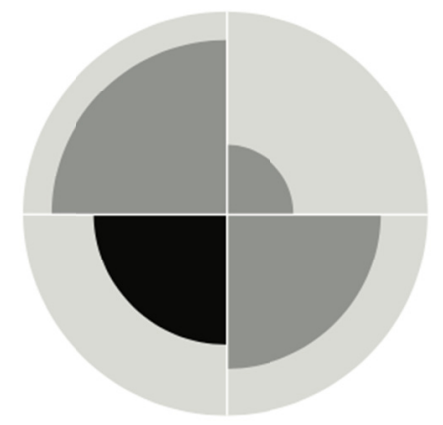

Figure 8. Transformation KF graph

The dispersion graph shows the variation on transformation between the 50 companies.

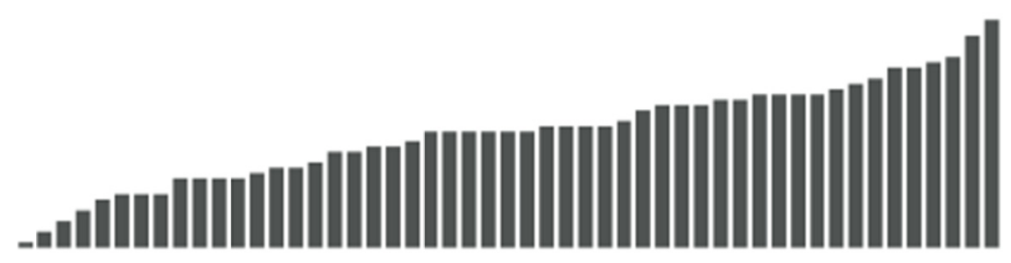

Figure 9. Transformation dispersion graph

\subsection{Insights from the Results}

All companies have performed vastly different in relation to the Inter Business framework for the different key-components, although some insights can be gathered from looking at the overall results for each principle.

\subsubsection{Inter Business}

Each of the principles draws upon valuable insights that are relevant to look at separately, but the Inter Business Index as a whole also provides insights on interconnectedness, how the principles work together to create the conditions for holistic sustainability. Each of the key-components interact and interconnect, and when applied together, provide insights on the multitude of aspects that needs to be considered as new demands and challenges arise for businesses.

For example, empathy provides the basis for the skills of transformation and system approach. The stakeholders 
are the foundation of all businesses, the reason for their existence. Their views and solutions are critical for businesses to be able to transform and to see their operations in a holistic way by incorporating a system approach. Without knowing the purpose of the business - the reason for existence - companies have a hard time evolving and adapting and respond to market transformation, rather than generating innovation and transformation themselves.

All of the top 50 Swedish businesses received a relatively low score, which indicates an opportunity to develop the key components in the external relations of the businesses.

\subsubsection{Purpose}

Looking at the results from the purpose analysis, it becomes evident that stakeholders understand an engaging purpose as being an extroverted one that connects to changing society in a sustainable way. Introverted purposes, along the lines of economic expansion or increased shareholder value, are viewed as non-engaging. However, to be seen as successful — a company must rank high on both engaging and alignment — positioning themselves in the upper right quadrant. This indicates that the brand is robust and that stakeholders find their engaging purpose to be credible in relation to the company expressing it. An interesting example is Preem (an oil company with the pronounced purpose: "To Lead Transformation Towards a Sustainable Society") that scores high on engagement, and low on alignment, meaning that they have an engaging purpose, but that stakeholders don't connect in a credible way with the company in question. We believe that this could be a result of Preem's work with fossil fuels.

\subsubsection{Empathy}

Understanding stakeholders and engaging in empathic meetings has through our analysis proven to be difficult for the analysed companies. There seems to be insufficient infrastructures for the knowledge and insight they provide about market, brand and performance - not least with regard to sustainability. The companies that succeed are ambitious in understanding and building relationships even with the most critical customer, show eagerness to gather information from stakeholders, and label that information as important pieces for future strategy and operations.

\subsubsection{System Approach}

The Inter Business analysis conducted makes it clear that a system approach to sustainability is very rare amongst the largest companies in Sweden. Not a single analysed company measures their impact towards the future, although some of them have a developed similar "tactics", for instance discussion about their footprint on the environment. Very few have a rigorous analysis of their role in the bigger context of society-or see themselves as actors that have the potential and/or responsibility to work for a more sustainable future for all. There is also a general lack in identifying macro trends, challenges that face their market, sector or context.

The companies mainly measure success in regards to sustainability in operations; most commonly, they look at how much emission they have been responsible for producing during the past three years, with the ambition to lower that relative figure over time.

\subsubsection{Transformation}

The transformation criterion, which the companies align with to the greatest extent, is innovation. Showcasing new inventions, new approaches and products were the most common way to communicate innovation in the 50 studied businesses. In the analysis we made an important distinction between sustainable innovations and non-sustainable innovations. For example, Sandvik launched a new kind of pipe used for transporting oil on oilrigs during the past year. According to the transformation principle, this cannot be viewed as an innovation, as it is innovated for a market that's unfit for future needs, demands and standards. Companies displayed less eagerness regarding the criteria that involves learning from mistakes - where very few companies scored any points at all.

\subsection{Material and Value for Corporate Governance}

The Inter Business analysis provides valuable insight to business leaders and corporate governance. As the index enables comparability over time and across sectors, the tool can easily share insights and knowledge to companies on how they can build and leverage their sustainability work, bringing theoretical knowledge to practice. The end product of the analysis is both a strength and risk analysis based on the key findings of the Index, as well as recommendations to the board and management team on how to assess and develop their company to future preparedness.

\section{Conclusions}

This article presents the concept of Inter Business and the Inter Business Index, a tool for measurement and comparability of holistic sustainability in businesses. Literature and previous research have concluded that there is 
a need to develop the concept of business sustainability by further applying a holistic and integrated approach. The academic field of sustainability research is well developed, but in our research we have identified a gap in how companies fail at navigating amongst the existing knowledge base, and applying it to their own core business. Instead, our research shows that the measurements and framework of business sustainability most commonly used today only captures context-specific aspects of sustainability. Still, public policy and stakeholders alike have even higher demands and expectations of companies' ability to act responsibly and contribute to local and global sustainable development. There is a clear need for a broader sustainability perspective and the concrete tools to achieve the ambitiously set goals. The integrated approach to sustainability needs to be further explored for businesses to become truly sustainable and move away from isolated and linear sustainability efforts. All dimensions of sustainability are interconnected, and strategic priorities in business need to align with these premises in order to meet new demands, but also to adapt to future challenges. The current norm in corporate sustainability work is not sufficient in tackling our shared global problems, and sustainability needs to permeate all aspects of business, instead of acting solely as an add-on or side note. There is a need for a new perspective that allows companies to integrate all aspects of sustainability, and to move away from the disconnection that we see in our research. Companies can contribute to human wellbeing and society through their core business, instead of consuming resources and creating unsustainable conditions for people, although there is a need for applicable methods and know-how. Businesses can play a significant role in changing the rules of their own game, and challenge existing structures jointly with other actors. Contemporary challenges are too large and complex to be solved by any single actor, but businesses have the means and capacities to generate large-scale impactful change.

The aim of Inter Business is to put forward a new way of viewing and understanding businesses and business sustainability, and to move business beyond the current concept of sustainability. This article can hopefully launch further discussions on the development of holistic business sustainability frameworks, and integrative approaches to sustainability.

\section{Acknowledgements}

We thank Shimeng Zhou and Frida Skog for assisting with processing of the text, and giving comments that greatly improved the manuscript.

\section{References}

Arnold, R. D., \& Wade, J. P. (2015). A Definition of Systems Thinking: A Systems Approach. Procedia Computer Science, 44, 669-678. http://dx.doi.org/10.1016/j.procs.2015.03.050

Asif, M., Searcy, C., Garvare, R., \& Ahmad, N. (2011). Including Sustainability in Business Excellence models. Total Quality Management \& Business Excellence, 22(7), 773-786. http://doi.org/10.1080/14783363.2011.585784

Barile, S., Saviano, M., Landolo, F., \& Calabrese, M. (2014). The Viable Systems Approach and its Contribution to the Analysis of Sustainable Business Behaviors. Systems Research and Behavioral Science, 31(6), 683-695. https://doi.org/10.1002/sres.2318

Caprar, D. V., \& Neville, B. A. (2012). "Norming" and "Conforming": Integrating Cultural and Institutional Explanations for Sustainability Adoption in Business. Journal of Business Ethics, 110(2), 231-245. http://dx.doi.org/10.1007/s10551-012-1424-1

Cowan-Sahadath, K. (2010). Business Transformation: Leadership, Integration and Innovation-A Case Study. $\begin{array}{llll}\text { International Journal of Project } & \text { Management, }\end{array}$ http://dx.doi.org/10.1016/j.ijproman.2009.12.005

Dyllick, T., \& Muff, K. (2016). Clarifying the Meaning of Sustainable Business: Introducing a Typology From Business-as-Ususal to True Business Sustainability. Organization \& Environment, 29(2), 156-174. http://dx.doi.org/10.1177/1086026615575176

Gao, J., \& Bansal, P. (2013). Instrumental and Integrative Logics in Business Sustainability. Journal of Business Ethics, 112(2), 241-255. http://doi.org/10.1007/s10551-012-1245-2

Gorry, G. A., \& Westbrook, R. A. (2011). Once More, With Feeling: Empathy and Technology in Customer Care. Business Horizons, 54(2), 125-134. http://doi.org/10.1016/j.bushor.2010.10.003

Hallin, J., Fredriksson, E., Altman, R., \& Zhou, S. (2016). Developing a Human Centered Business Index-Leading with Purpose, Empathy, Systems-Approach and Resilience in "Business Beyond Sustainability". European Public \& Social Innovation Review, 1(1), 33-43.

Hollensbe, E., Wookey, C., Hickey, L., George, G., \& Nichols, C. V. (2014). Organizations with purpose. 
Academy of Management Journal, 57(5), 1227-1234. http://doi.org/10.5465/amj.2014.4005

Holt, S., \& Marques, J. (2012). Empathy in Leadership: Appropriate or Misplaced? An Empirical Study on a Topic that is Asking for Attention. Journal of Business Ethics, 105(1), 95-105. http://doi.org/10.1007/s10551-011-0951-5

Høgevold, N. M., \& Svensson, G. (2016). Framing the Development and Directions of Business Sustainability Efforts. Corporate Governance, 16(4), 709-725. http://doi.org/10.1108/CG-11-2015-0148

Metcalf, L., \& Benn, S. (2012). The Corporation is Ailing Social Technology: Creating a "Fit for Purpose" Design for Sustainability. Journal of Business Ethics, 111(2), 195-210. http://dx.doi.org/10.1007/s10551-012-1201-1

Müller, A., \& Pfegler, R. (2014). Business Transformation Towards Sustainability. Business Research, 7(2), 313-350. http://doi.org/10.1007/s40685-014-0011-y

Pahurkar, R. N. (2014). The Comprehensive Approach for Creativity and Innovation-Enhancement and Sustainability in Social Enterprises. Journal of Management and Sustainability, 4(2). http://dx.doi.org/10.5539/jms.v4n2p111

Pavlovich, K., \& Krahnke, K. (2012). Empathy, Connectedness and Organisation. Journal of Business Ethics, 105(1), 131-137. http://doi.org/10.1007/s10551-011-0961-3

Philip, G., \& Mckeown, I. (2003). Business Transformation, Information Technology and Competitive Strategies: Learning to Fly. International Journal of Information Management, 23(1), 3-24. http://dx.doi.org/10.1016/S0268-4012(02)00065-8

Rake, M., \& Grayson, D. (2009). Embedding Corporate Responsibility and Sustainability-Everybody's Business. Corporate Governance, 9(4), 395-399. http://doi.org/10.1108/14720700910984945

Rezaee, Z. (2016). Business Sustainability Research: A Theoretical an Integrated Perspective. Journal of Accounting Literature, 36, 48-64. http://doi.org/10.1016/j.acclit.2016.05.003

Rüdiger, H. (2011). Integrating Corporate Responsibility and Sustainable Development-A NormativeConceptual Approach to Holistic Management Thinking. Journal of Global Responsibility, 2(1), 8-22. http://dx.doi.org/10.1108/20412561111128492

Schaltegger, S., Lüdeke-Freund, F., \& Hansen, E. G. (2016). Business Models for Sustainability-A Co-Evolutionary Analysis of Sustainable Entrepreneurship, Innovation, and Transformation. Organization \& Environment, 29(3), 264-289. https://doi.org/10.1177/1086026616633272

Schultz, R. J. (2014). Framing the Organization's Purpose with Its Ultimate Goals in Mind. Global Business and Organizational Excellence, 33(3), 46-55. https://doi.org/10.1002/joe.21543

Symons, C., \& Lamberton, G. (2014). Building a Social Case for Business Sustainability. Journal of Economic and Social Policy, 16(2), 186-209.

Svensson, G., \& Wagner, B. (2011). Transformative Business Sustainability Multi-layer Model and Network of $\begin{array}{lllll}\text { E-footprint Sources. } & \text { European Business }\end{array}$ http://dx.doi.org/10.1108/09555341111145735

Wagenhals, S., Garner, W., Duckers, L., \& Kuhn, K. (2014). Sustainability Index with Integrated Indicator Dependencies. Business, Management and Education, 12(1), 15-29. https://doi.org/10.3846/bme.2014.02

White, A., Yakis-Douglas, B., Helanummi-Cole, H., \& Ventresca, M. (2017). Purpose-Led Organization: "Saint Antony" Reflects on the Idea of Organizational Purpose, in Principle and Practice. Journal of Management Inquiry, 26(1), 101-107. https://doi.org/10.1177/1056492616647481

White, M. A. (2013). Sustainability: I know it when I see it. Ecological Economics, 86, 213-217. https://doi.org/10.1016/j.ecolecon.2012.12.020 


\section{Appendix A.}

\section{Empathy Social media Analysis}

Examples of different interactions and responses wit their respective category. Most of the interactions are translated from Swedish. The names of the companies, as well as names of the persons interacting with the companies and telephone numbers, are removed or marked with XX.

\subsection{Attacking/Offensive:}

\subsection{1}

[Stakeholder:]

Why are you involving other companies? He is still employed by you, even if he only works hours.

[Response from company:]

Be honest. You don't even like us, do you?

\subsection{Defensive:}

\subsection{1}

[Stakeholder:]

God damn it, its been three weeks now and still no refund.

[Response from company:]

Hi again XX! The money is on its way because the refund is done. We have no possibility to speed up the refunding process, even though it seems to have taken quite some time in your case. But as I said last week when you contacted us, the money should be on your account during this week. /XX

\section{2 .2}

[Stakeholder:]

Strange! Even when I try to log on to the mobileapp, I still get an error message saying that XX can't be reached.

[Response from company:]

Well that is strange, we have no other reported errors. But is I said earlier, call the bank on the telephone and see if they can help you. /XX 


\subsection{Sympathetic:}

\subsection{1}

[Stakeholder:]

I would probably get a quicker response with mail from the royal house, than from the person responsible for my matter at your company.

[Response from company:]

Sad too hear. Is it still a long call waiting?

\subsection{2}

\section{[Stakeholder:]}

This is one of the worst webpages that exists. It's almost impossible to log on. It is so annoying.

[Response from company:]

Hi XX! I'm sad to hear that you feel that our webpage isn't good. Please describe your experience on why you feel that it isn't good and I will forward your opinion to the affected department. Are you having troubles logging on to My Pages? Please submit your customer information in a message so we can help you to log on. /XX

\subsection{Empathic:}

\section{4 .1}

\section{[Stakeholder:]}

Is there a manned station in Borensberg?

[Response from company:]

Hi XX! I have to apologize because I have just received information on that the station in Borensberg has shut down. Nearest manned station is Mantorp. Hope you can overlook this. Have a nice day and a lovely weekend! //XX

\section{4 .2}

\section{[Stakeholder:]}

Seriously? I've been waiting on hold for 29 minutes and 46 seconds when you all of a sudden say "Welcome too $\mathrm{XX}$, we have now closed". 8 minutes passed $5 \mathrm{pm}$ ? Seriously? I have spent half an hour of my life for NOTHING? Totally useless...

[Response from company:]

Hi XX! I understand you frustration if you waited on hold and didn't get any response from us. Please send a private message here on Facebook with your customer number and what your questions is about and I will see that one of my colleagues contacts you tomorrow. Best Regards, XX, XXX 


\subsection{Neutral:}

\subsection{1}

[Stakeholder:]

How do you inform in stores the origin for all of the dairy products, including hard cheese?

[Response from company:]

Amongst some things, we mark the packaging. We are counting on marking around 400 new packages this year with the marking from Sweden.

\section{5 .2}

\section{[Stakeholder:]}

I have registered on your webpage, but I couldn't fill out my cellphone number (the box was missing) for text messaging when my orders are ready to be picked out. How come?

[Response from company:]

Hi XX! You can add the cellphone number afterwards under "user account" at "My XX". The choice to get a text with delivering information is done first when you place an order. Please contact our customer service at XXX-XXX for more help.

\section{Copyrights}

Copyright for this article is retained by the author(s), with first publication rights granted to the journal.

This is an open-access article distributed under the terms and conditions of the Creative Commons Attribution license (http://creativecommons.org/licenses/by/4.0/). 